\title{
Imagining and enacting the future of the German energy transition: electric vehicles as grid infrastructure
}

\section{Alexander Wentland}

To cite this article: Alexander Wentland (2016) Imagining and enacting the future of the German energy transition: electric vehicles as grid infrastructure, Innovation: The European Journal of Social Science Research, 29:3, 285-302, DOI: 10.1080/13511610.2016.1159946

To link to this article: $h$ ttp://dx.doi.org/10.1080/13511610.2016.1159946

曲 Published online: 15 Mar 2016.

Submit your article to this journal $\pi$

Џll Article views: 86

Q View related articles 5

View Crossmark data ¿ 


\title{
Imagining and enacting the future of the German energy transition: electric vehicles as grid infrastructure
}

\author{
Alexander Wentland ${ }^{\mathrm{a}, \mathrm{b} *}$ \\ ${ }^{a}$ WZB Berlin Social Science Center, Berlin, Germany; ${ }^{b}$ Department of Sociology, Technical \\ University of Berlin, Berlin, Germany
}

(Received 15 September 2015; final version received 20 February 2016)

\begin{abstract}
The electrification of transportation in Germany has failed so far, but the disappointment has given way to more radical visions and new coalitions. Utilities, grid operators, and ICT companies have started to challenge the traditional image of the car. In their future scenarios, transportation, energy, and communication infrastructures must be aligned in order to achieve a sustainable society. This paper explores the co-production and enactment of this technological vision using the analytical framework of sociotechnical imaginaries. First, I describe how the idea of the electric vehicle as energy infrastructure was able to take hold within the German expert community. To understand how this approach might transform the existing mobility and energy practices, I examine two of the first R\&D experiments that have enacted this vision in two radically different ways. Both reflect unarticulated assumptions about social life, including implicit cultural notions of selfdetermination, ownership, living arrangements, privacy, and control.
\end{abstract}

Keywords: electric vehicles; energy transition; smart grid; sustainability; infrastructures; imaginaries; futures

\section{Introduction}

Germany's attempt to become the lead market and lead producer for electric vehicles (EVs) has failed so far, but the disappointment has given way to more radical technological visions and new actor-coalitions around them. In recent years, a new set of players has emerged, who had no previous involvement with the automobile industry. Some utilities, electrical grid operators, and ICT companies have started to challenge the traditional image of the car. These actors seek to create new markets and business models by envisioning a greater purpose for the EV altogether. In their future scenarios, transportation, energy, and communication infrastructures must be aligned in order to achieve the goal of a sustainable society. They argue that if EVs were fully integrated into a decentralized, digitally enhanced electrical grid, their mobile batteries could play a crucial role in increasing the share of energy sources that are as of yet susceptible to load fluctuation, such as wind and solar in a future electricity system. At the same time, the bidirectional vehicle-togrid (V2G) charging technology would benefit the electrification of transportation, as drivers could be offered financial incentives for making their cars available to the grid and thereby stabilizing loads.

*Email: wentland@wzb.eu 
The mutually beneficial convergence between transportation and electrical power systems has become an admittedly controversial part of the German energy transition (Energiewende) narrative. Although the actual deployment of vehicles has fallen behind the expected figures, this technological vision has gained popularity among industry experts, urban planners, and high-tech entrepreneurs alike. The actors involved not only propose novel technical arrangements. They depict a new desirable future, where sophisticated innovations benefit both the environment and the economy. Even though it remains unclear when EVs will turn a profit, the imagination around "the car of the future" has become more vibrant and contested. With technologies and new corporate alliances coming together, the traditional image of the automobile, its design, purpose, and meaning, is being challenged as well.

Based on an analysis of expert discourse, interviews, and ethnographic fieldwork, I describe how the vision of the EV as energy infrastructure was able to take hold within the German industry and policy community, in spite of the persistent doubts regarding its benefits and feasibility. However, looking at expert discourse and corporate promises alone illuminates only half of the picture. To understand how such a technological concept might transform the existing practices around mobility and energy consumption in the long run, I proceed to examine two of the first R\&D experiments that have enacted the same vision in two radically different scenarios. Such a dual methodological approach means considering the imagined futures behind the innovation more explicitly and taking into account the cultural constitution of the energy transition beyond government programs and economic calculations.

Most of the recent literature on the electrification of transportation has focused on drivers, barriers, and obstacles of this transition from a co-evolutionary perspective (Geels 2012; Bakker and Trip 2013; Sierzchula et al. 2014), but has neglected the multiplicity of competing imagined futures of this technology. ${ }^{1}$ This type of analysis calls for a theoretical framework that pays equal attention to the materiality, meaning, and morality of a technological vision. The notion of "sociotechnical imaginaries" (Jasanoff and Kim 2009 , 2015) explicitly foregrounds this interplay between emerging technologies and cultural values. It has been securely established within science and technology studies (STS), but has not been widely adopted in the field of innovation studies yet. For this reason, this paper also aims to show how sociotechnical imaginaries provide a useful analytical resource for investigating into the formative but often implicit collective understandings about desirable mobility and energy futures.

Germany presents a perfect empirical case study with regard to both areas of social life and social order. Strong and contradictory currents of sociotechnical imagination run below the seemingly well-organized transition efforts: Germany's economy is, to a large degree, based on auto manufacturing and car culture has a strong grip on everyday life. At the same time, the country has a long-standing environmental movement and has rapidly increased its share of renewable energy sources within the past decades. Perhaps because German's industry, politics, and culture are almost inseparable from the dominant regime of automobility, the electric car has been struggling to gain ground. Probing into this field of tension can help to understand the cultural implications and possible trajectories of sociotechnical change.

\section{Imagining and enacting future technology}

Scholars interested in the social construction of technology have been continuously pointing out the productive ambiguity of societal "guiding visions" (Dierkes, Hoffman, and 
Marz 1996) or entrepreneurial "vanguard visions" (Hilgartner 2015), also with regard to the automobile (Canzler 2008; Rammler 2008). Technological visions imply certain roles for the parties involved and provide often heterogeneous coalitions with a shared understanding of chances and risks. Adding more nuance to this notion, Rammert (2002) further distinguishes between "visions of function and use" and "concepts of engineering and design." The more an innovation is characterized by an intricate "circle of uncertainties" (Rammert 2002, 176-78), the greater the influence of relatively abstract visions becomes in the process of technological and organizational selection. A number of studies have looked more closely at the interplay between inventors and the expectations of their supporters such as policymakers, venture capitalists, and the general public (van Lente 1993; Borup et al. 2006; Konrad 2006). They consider hopes, hypes, and promises to be cultural devices that mobilize "the future into the present" (Brown 2003, 5).

Extending this notion to society at large, Jasanoff and $\operatorname{Kim}(2009,2013,2015)$ have shown that visions and expectations tap into larger cultural currents that extend beyond specific technological regimes. Those often competing imaginaries not only influence the designs and inscriptions of novel artifacts but also constitute the identity of modern post-industrial societies, which are imbued with scientific knowledge and rely on pervasive large technical systems. Building on the work of Appadurai (2013) and others (Anderson [1983] 2006; Taylor 2004), Jasanoff defines sociotechnical imaginaries as "collectively held, institutionally stabilized, and publicly performed visions of desirable futures, animated by shared understandings of forms of social life and social order attainable through, and supportive of, advances in science and technology" (Jasanoff 2015, 4). This definition shifts the emphasis from specific, deliberate sustainability transitions back to the question of how collective understandings of society shape technology and vice-versa. Starting from this premise, my goal is to explore the less visible underpinnings of transitions "in the making" (Callon [1987] 2012) and highlight the variety of ways in which groups of actors assemble and stabilize a technology such as V2G outside the lab (Law 1994).

\section{Approach, data, and methodology}

I use the framework of sociotechnical imaginaries as a point of departure for my dual approach, focusing on both the discursive articulation of the technological vision within the expert community and the enactment of this vision in two concrete pilot projects. The data presented here stems from interviews, the collection of documents, and participant observation in Germany. The time period covered represents the most recent and still ongoing episode in the electrification of transportation from 2008 to 2015. More specifically, I have conducted continuous ethnographic fieldwork over the course of three years (between 2012 and 2015), including more than 30 recorded interviews and behind-the-scenes conversations within the German EV community. The main results presented here are based on an extensive document analysis. My data include public speech transcripts, observations, artifacts, government reports, commercial materials, visual advertisements, and presentations at trade fairs.

During my fieldwork, I looked into various vehicle-grid application scenarios, prototypes, and public-private partnerships that have been proposed by companies across different sectors of industry, ranging from car manufacturers to utilities companies and IT firms, including established players as well as small start-ups. The two experimental R\&D projects discussed in the second part of this paper have been selected from a variety of cases based on their degree of sophistication, maturity, and visibility. I used the technique of 
theoretical sampling (Draucker et al. 2007) to select two cases that were similar in the basic technology used (vehicle-to-grid/home), but diverged in their application scenarios. The two prototypes I describe are the "swarm battery" experiment conducted by Volkswagen and the utility LichtBlick and the "D.I.V.A." system marketed by the German start-up company e8energy.

For the analysis of my interview and document data, I employed the methodological toolkit of contemporary grounded theory (Corbin and Strauss 2008; Charmaz 2006) and sociological discourse analysis (Keller 2012). I have paid close attention to rhetorical devices such as metaphors (Lakoff and Johnson 2003), which turned out to be a particularly productive pathway into the imagined futures mobilized in engineering, policy discourse, and corporate marketing. In a recent turn, Clarke (2005) made grounded theory methodology more attune to the inquiry into technology and the sociomaterial relations resulting from it. Rethinking grounded theory in this way eliminates the epistemological barriers between the document analysis and participant observation (Clarke 2005, 58). My dual approach to this case study builds on this key element. I consider my empirical account, at its core, to be a multi-sited ethnography (Hine 2007) of imagined futures while they are still unfolding. As I show in the following sections, such imagined futures are co-produced and sustained by various kinds of communications, practices of ordering, and the materiality of local technical systems.

\section{Germany's shaky energy and transportation transitions}

The transition toward a decarbonized society has been a complicated technical, economic, and political issue in many European countries. The German case provides a perfect example for this. While the government is currently lagging behind the EU goals ${ }^{2}$ or meeting some of them with little effort due to the historic dismantling of ramshackle Eastern German industries (Fraunhofer ISI 2001, 7-11), parts of the population has been concerned with wind and solar power wholeheartedly since the green energy citizen movement emerged in the early 1980s (Rucht and Roose 2001). To some, the use of solar panels became a political statement against a nuclear and coal based energy system. In addition, hundreds of local energy cooperatives have been founded since then, some of which have become important players on the German electricity market (Schreuer and Weismeier-Sammer 2010). In 2014, 27.8\% of the energy produced came from renewable sources (BMWi 2015). While the vast majority of the population supports the expansion of renewables, the German federal state has been muddling through the energy transition. For instance, all German nuclear power plants will gradually shut down by 2022, while fossil-fuel power stations are supposed to remain in a key position for satisfying minimum demand.

It has been argued, however, that the problem is not so much generating but transmitting, regulating, and storing electricity from renewable energy sources. Since the supply of wind and solar power is by its nature inconsistent in time and space, the growing share of renewables in the energy mix has already put unprecedented pressure on German grid operators and utilities to adapt to the new circumstances, according to a number of energy experts (Buchan 2012; Huenteler, Schmidt, and Kanie 2012). The restructuring of the electrical grid has become a large-scale real-world experiment with a high degree of uncertainty (Gross and Mautz 2015). Although many of the old players are resisting the current transformation, there is hardly any doubt that in the future electricity generation will be regionally dispersed and decentralized, most likely not aligned with electricity demand. For this reason, many utilities, grid operators, and policymakers argue that, 
besides the long-distance transmission, Germany's local storage capacity for surplus energy would supposedly become the long-run bottle neck for the increase of renewables in the higher double digits (RAP 2015).

While the share of renewable energy sources has steadily increased over the past decades, the transportation sector is lagging behind significantly. In terms of overall emissions, road mobility is one of the few sources of $\mathrm{CO}_{2}$ that has shown hardly any overall improvement toward a decarbonization (OECD/ITF 2015, 50). In Germany, the share of renewable sources of energy in this area - biofuel and electricity - is languishing around 5\% (BMWi 2015). This might seem surprising, considering the effort that went into promoting "electric mobility" (Elektromobilität). In 2008, Germany set out to become a lead market, with 1 million plug-in electric cars rolling on the streets by 2020 and the lead producer within the international EV industry, investing 1.5 billion Euros to that end (Bundesregierung 2009; Acatech 2010). The electrification of transportation has become a self-declared national priority (Bundesregierung 2011). This step was not taken solely for environmental reasons. The government was afraid German car manufacturers could lose their dominance on the world market, if they did not invest into the electrification of their next-generation vehicles (NPE 2010). The high oil price in the mid2000s and international agreements on $\mathrm{CO}_{2}$ emissions were drivers that pushed the EV back to the forefront of environmental and economic policy.

So far, the results have disappointed experts and policymakers alike. In 2014, the market share remained at a meager $0.4 \%$. In an optimistic calculation, including plug-in hybrids, the government estimates 24,000 EVs on the roads (NPE 2014), a relatively low number, even in comparison to smaller countries such as the Netherlands and Norway. The actual consumer market penetration appears even more problematic, considering the fact that the majority of the EVs registered are part of corporate fleets or owned by car-sharing businesses. So far, as an innovation, in the sense of a widely diffused and accepted novelty (Rogers [1962] 1983), the electrification of transportation in Germany has failed and does not appear to be close to its tipping point, since consumers continue to regard EVs as far too expensive and limited in their capabilities.

\section{A new imagined future for an old technology}

In the following section, I argue that because of the current disappointment with the cumbersome deployment of EVs, new players with new visions of the electric car have been able to take the stage within the German expert community. For some engineers, policymakers, and urban planners, the solution to the stagnation of both the electrical grid and transportation lies in between the two sociotechnical systems. Local storage capacities for energy from renewable sources might in fact be the missing component in a modern energy infrastructure. Since EVs are large mobile batteries, proponents of this idea advocate the deployment of more sophisticated, bidirectional charging interfaces.

This approach is most often referred to as vehicle-to-grid (V2G). The basic R\&D originated from a research group led by engineer and policy advisor Willett Kempton at the University of Delaware (Kempton et al. 2001; Sovacool and Hirsh 2009). Kempton argues that EVs could be integrated into a decentralized, ICT-based electrical smart grid to coordinate supply and demand. Through this kind of bidirectional, controlled charging, they could play a crucial role in increasing the share of renewables in the future energy mix (Loisel, Pasaoglu, and Thiel 2014). Supporters claim that this would also raise consumer interest in electric cars. If drivers made their cars available to the utilities and grid operators, they would be compensated financially. This could lower the costs of ownership 
significantly, the argument goes. The technological vision of the EV as energy infrastructure has grown into a multi-sited phenomenon, independent from the developments in Delaware.

This vision has attracted a new set of players who had no previous involvement with the automobile industry or infrastructure. In Germany, the federal government brought utilities and energy technology companies such as E.ON and Siemens to the table early on as part of the National Electric Mobility Platform (BMU) in 2010. In the following years, the remaining three out of the "big four" utility companies Vattenfall, RWE, and EnBW joined the bandwagon. Although none of these corporations shifted their overall strategy toward sustainable energy systems, all of them launched pre-commercial R\&D projects related to the next generation of EVs. In most of the interviews with utilities and electric power distributers, they doubt the benefit of V2G for the current energy system but see economic potential in future applications. They are not only in the position to provide the fuel for these vehicles but also to utilize them for additional functions such as frequency regulation and peak shaving, when the grid infrastructure becomes dominated by renewable sources.

Modernizing the electrical grid in the proposed way has sparked energy technology and ICT companies' interest in V2G business models. Siemens initially promoted EVs as the corner stone of their "city of the future" campaign, but dropped it in 2013 due to internal streamlining. However, as a technology analyst put it in an interview, "when Elon Musk gets serious with Tesla and Solar City, this is going to be the future and they [the German energy industry] cannot afford to let this [opportunity] pass by again" (interview at a EV conference in 2015). When looking at major conferences and promotional events over the past five years, it becomes apparent how much the discourse has shifted from cost and battery issues, to an imagined future inspired by Silicon Valley high-tech hopes. ICT companies are already invested in advanced driver assistance and communication systems for cars. From their perspective, EVs seem even more lucrative. EV drivers interacting with buildings and the electrical grid through charging interfaces represent an entirely new group of customers, who can be targeted with novel products and services. A few startup firms have already anticipated the possibilities for new business models within this emerging market. The big players in the ICT industry such as Google and Apple are about to follow. They are determined to not just provide computers for cars but rather to seamlessly integrate the vehicles into their soft- and hardware ecosystems.

After decades of incremental innovation and relatively static structures within the automotive industry, new conceptions of what the car's design and purpose can be have been proliferating. Influential authors and public speakers such as the self-declared "chief futurist" Lars Thomsen or former General Motors R\&D executive Lawrence Burns have become powerful voices within the EV expert discourse. In his 2010 book Reinventing the Automobile (2010) Burns and other industry experts propose nothing less than to "transform the DNA" of the automobile and the electrical grid:

Because of the codependencies among automobiles, energy infrastructure, communications infrastructure, and governments, it will be necessary to align incentives, form coalitions of stakeholders, and build a broad consensus around a common vision of the future of personal urban mobility. This common vision must be constructed around a "system-of-systems" framework, with widely accepted standards enabling interfaces among systems, and the increase in value of a system for every user as it grows ... motivating investment and powering rapid system growth. (Mitchell, Borroni-Bird, and Burns 2010, 7)

This suggested coupling of formerly separate large sociotechnical systems is different from the general understanding that electric cars should be powered by "green" energy in order 
to make environmental sense. The idea is that carbon-free electricity and the electrification of transportation depend upon each other, in terms of a co-evolutionary advantage. Some corporate public relations publications have invoked the biological image of a "symbiosis" of energy and transportation infrastructures, which now can be found across a variety of German expert presentations and (online) trade journals. The metaphor reflects a grand technological vision, employed by some of the actors in the field, who are mainly entrepreneurial engineers, urban planners, futurists, a few start-ups, and future business divisions of technology corporations - most of which are not originally based in the car manufacturing or transportation industry.

Their vanguard vision of interconnected infrastructures has become an admittedly controversial part of the German energy transition narrative. Presently, the large-scale commercial deployment of the elements required for such a "system-of-systems" seems a long way off. There is little to see in the showrooms or the national media coverage. However, the abstract notion of a symbiosis between mobility, the electrical grid, and communication systems has become influential in parts of the German expert and policy community. As the German federal government's most recent report on the progress of EV deployment states emphatically in the very beginning: "Electric mobility is the global key to a climate friendly transformation of mobility and, in Germany, it is part of the transition toward renewable energy" (NPE 2014, 3).

This imagined future has revitalized hopes and expectations in a time of general disappointment and bleak outlooks across the notorious "valley of death," which a pre-product has to survive before it becomes profitable or perishes (LeVine 2015). Regardless of the many known issues with V2G systems, ${ }^{3}$ the German state as well as parts of the industry dedicated significant efforts and funds to marrying transportation and the electrical grid. An almost Wittgensteinian Gestalt switch has turned the perceived image of the electric car upside-down. EV technology had fallen into oblivion for more than a century (Anderson and Anderson 2010). Suddenly, a formerly seemingly inferior substitute for the internal combustion engine could be re-imagined as a high-tech hope for the overall transition into a more sustainable society and, from the perspective of the commercial challengers, a promising area with potentially enormous profits. For policymakers, the changed narrative resonates with the imaginary of a "green new deal," which promises Germany the chance to meet both environmental goals and economic ambitions.

\section{Enacting the EV as energy infrastructure}

The challengers in the electrification field seek to re-imagine the electrification of transportation through ICT-based vehicle-grid innovations. Their technological vision has become part of the EV policy narrative and - to some degree - of the sociotechnical imaginary of the German energy transition. However, analyzing expert discourse and corporate campaigns leaves the picture incomplete. As I argued above, it is equally important to observe the material and performative enactment of such technological visions. Hecht, among others (Felt 2015), stresses the observation that ideas "do not grow by themselves." They "must be actively cultivated in order to persist." As a consequence, "articulating and rehearsing these ideas often reformulates them" (Hecht 2009, 12). Once they have extended to real life application scenarios, novel technologies must align with existing material infrastructures as well as meaningful cultural narratives in order to succeed. Electricity and mobility have been separate domains based on different arrangements of materiality, practices, and politics for a long time. How will the proposed integration of EVs into the electrical grid effect mobility, its infrastructure, and the culture it is imbued with? 
To understand how a technological vision might transform mobility and electricity consumption practices, I proceed to examine two German R\&D experiments that have enacted the same vision in two radically different scenarios. I have deliberately chosen these two cases from a broad range of similar R\&D projects based on their degree of sophistication, maturity, and visibility. Both cases build on bidirectional charging interfaces but diverge in their application scenarios. Each articulated scenario carries certain assumptions about the involved technologies, their purpose, and their prospective users. The R\&D experiments I am about to describe tap into larger, pre-existing collective cultural currents. They convey shared understandings of forms of social life, which become institutionally stabilized through the repeated performing of desirable futures. As I want to demonstrate, both the discursive shifts within the expert community and the early-stage R\&D projects can adhere to the same powerful technological idea. However, through the process of assembling and enacting it, this vision reveals its ambiguity, allowing actors and their networks to align with competing sociotechnical imaginaries.

\section{The swarm scenario}

The first R\&D project I examine was carried out by Volkswagen and the utility LichtBlick between 2013 and 2015. LichtBlick is one of the biggest owners of solar and wind power plants in Germany. Both companies have shown great interest in EV storage solutions and smart grid applications. Together with notable partners from research institutes and energy technology companies, the joint venture developed a technical system that pools electric cars virtually into a "swarm battery" (Schwarmbatterie), a distributed storage system for renewable energy sources. The German federal government selected the test to be one of its "beacon projects" for electric mobility and subsidized it to the tune of 7 million euros.

In 2014, the Berlin-based pilot test took off. The consortium installed specialized charging stations at the homes and work places of 20 Volkswagen test drivers. According to the documentation, the most complicated problem was developing software capable of coordinating the process of charging and feeding electricity back into the electrical grid on demand. LichtBlick's engineers succeeded in creating an ICT platform, which they dubbed "swarm conductor" (SchwarmDirigent). In a smartphone application developed by Volkswagen, the drivers scheduled their trips. They could set a minimum charge they wanted to keep for spontaneous activities or emergencies. The EVs took part in the frequency regulation of the electrical grid when parked at home or at work. Depending on how much the grid operator utilized the vehicle's storage, it compensated the test driver financially (Volkswagen, April 16, 2014). Shortly afterwards, LichtBlick extended the "swarm battery" business model to stationary batteries inside private, solar-powered homes.

This enactment of V2G blurs the notions of car drivers, users, consumers, and producers. Within the swarm scenario, drivers mostly become consumers of energy and users of ICT hard- and software. At the same time, they become temporary producers of storage capacity. The "prosumer" has emerged as a figure in recent debates on digital media (Ritzer and Jurgenson 2010) and energy infrastructure (Grijalva and Tariq 2011). However, the question of whether or not the blurring of boundaries between consumer and producer has empowered the user or rather created new channels of control remains controversial (Comor 2011). In this specific pilot project, the system of virtually connected and centrally managed batteries integrates EVs as well as stationary capacities into one higher order organism, as the biological metaphor of the "swarm" implies. Drivers are financially compensated for making their car's battery available for the grid. Within this 
arrangement, centrally managed charging, roaming, and billing become a crucial element of private transportation. At a certain point, if renewable energy were to become the main source of power, EVs would no longer be additional resources for the grid operator. They would turn into an indispensable element required to balance supply and demand of the electrical grid, which would then require a detailed real-time anticipation of mobility patterns in order to estimate and control the necessary storage capacities.

This may constitute certain tensions considering the deeply rooted culture that has built up around the car over the course of a century. Automobile culture sustains key discourses of what constitutes a good life. To many drivers, a car is not just a mundane means of transportation or a mobile battery. Since the beginning of the world's "love affair with the car" this often romanticized symbol of late-industrial modernity has been synonymous with autonomy, self-determination, and the privacy of the car's interior (Featherstone 2004). The dominant sociotechnical imaginary of private transportation has inspired powerful artistic and literary expressions. From the novels of Scott Fitzgerald to the American road movie genre, it has provided symbols of what is necessary for the "citizenship of mobility" (Urry 2004, 26).

The swarm metaphor suggests that there is no center that exercises control over its various agents. Only some kind of elusive "swarm intelligence" ensures the seamless interaction of otherwise independent agents in order to guarantee the functioning of the system. On the infrastructural level, however, the coordination of the individual batteries is managed through a commercial server, a centralized information hub upon which the entire network relies. The swarm conductor monitors every connected vehicle, home, and charging station. After all, distributed systems of supply and demand require "centers of calculation" (Latour 1986) that raise issues of ownership and control.

Even though the engineers assure that individual mobility is the number one priority of the project, the image and purpose of the car from the perspective of a utility and grid operator is different. The swarm scenario applies the logic of (electrical) grids and (communication) networks to the conventionally individualistic and private notion perpetuated by automobile culture. The car is no longer envisioned as an autonomous unit that equips its driver with the necessary horsepower to follow his or her passion and will. It is part of a complex, mostly invisible ecosystem of solar panels, smart chargers, local electrical distribution systems, and computer servers. The individual driver's image of a desirable car, or, rather, how car companies imagine their customers viewing their products is no longer the center of attention. What matters is the big picture, the transition toward a sustainable society, which is largely based on what and how utility companies and grid operators "see," similar to how Scott (1998) and Ferguson (2005) interpret the state's or an oil company's views of the world.

\section{The autarky scenario}

The second scenario directly appeals to the notion of autonomy, the ownership, and control over the pieces of both individual mobility and the electricity supply. The Hamburg-based start-up e8energy is currently marketing their prototype generation of individual vehicleto-home solutions. Their product name "D.I.V.A." stands for "Decentral. Intelligent. Versatile. Autarchic." The company equips the buyer's house with a charging connector, which can charge the battery as well as feed energy back into the system, similar to the technology used by the utility LichtBlick. Unlike the "swarm battery" arrangement, this system consists of most likely an ordinary installation of solar panels on the roof and a terminal to regulate and schedule the interaction between the building and the vehicle. 
Again, the software component is crucial. This time, however, it is mostly in the hands of the house owner, respectively the driver. The powerful image of the autarky scenario suggests that the user potentially frees himself or herself entirely from the providers of both electricity and gasoline.

The image of "going off the grid" gains more attraction the further the necessary technology develops and the more affordable it becomes. But, in fact, it is nothing new. The notion of developing energy systems for achieving social and political independence dates back to the early post-World War II years (Laird 2003). In Germany, the pioneers of the environmental and countercultural movements championed this cause effectively in the early 1980s. They envisioned their homes and communities to be independent from the perceived economic greed and environmental ignorance of the nuclear and fossil-fuel industry. Although vehicle-to-home resonates with progressive environmental values, the autarky scenario also validates the conservative arrangement of private home and car. The traditional twentieth century imaginary of the middle class has often been identified with both suburban living and individual mobility. This combined sociotechnical arrangement reflects the ideal of economic, political, and cultural autonomy by means of private property.

Other R\&D projects push the autarky scenario beyond the private household, while evading the grand vision of a large-scale system-of-systems. They have in mind the aggregated potential of larger organizational entities such as neighborhoods, small communities, and companies, or, more generally, the owners of premises where solar and wind energy generation can be combined with larger fleets of electric cars. This local "micro smart grid" approach would especially apply to dense, urban environments. Some application scenarios aim at shopping malls or commercial districts as potential clients for such micro-grid solutions. In that case, the owner of the premises rather than the driver might be the main beneficiary. A shopping mall visitor would give away control over his or her vehicle, while the parking lot operator can use it for various purposes, for example, balancing the building's electricity demand.

At this point, it becomes obvious that the two scenarios are poles in a space of possibility along at least two sociotechnical imaginaries and the field of tension in between. One I would refer to as the imaginary of seamless interconnectivity, synergy, and delegation to higher order systems. The second could be described as the imaginary of autonomy and self-determination in a world that has become increasingly shaped and governed by large technical systems. These rather utopian imaginaries show themselves in sometimes banal everyday life questions such as convenience versus control or ownership versus delegation. As the two described scenarios suggest, the envisioned "symbiosis" of mobility, energy, and communication technology can be enacted and materialized in assemblages of users, artifacts, and practices that ultimately head into different directions. Like with most innovations, there will be different groups of users who will prefer one over the other (Bijker, Hughes, and Pinch [1987] 2012). Some users might embrace a technically sophisticated, service-based model; other users could seek the small-scale, high-maintenance solution. Most likely, users will appropriate and modify any given infrastructure to suit their needs (Oudshoorn and Pinch 2003; Coutard and Guy 2007). It is also safe to assume that user groups will base their choice on both financial incentives and beliefs such as environmental protection and privacy.

\section{Symbiotic infrastructures and their discontents}

Everyday life depends on infrastructures. The term, as I use it here, encompasses both the so-called hard infrastructure, the highways, gas stations, power lines, and transformers as 
well as its culture, politics, and power structures - ironically often referred to as the "soft" ones. In fact, both are inseparable, as STS scholarship keeps reminding engineers and sociologists alike (Hommels 2005; Rowland and Passoth 2015). Infrastructures often turn into areas of contestation (Egyedi and Mehos 2012). But most of the time, infrastructures and the technologies behind them tend to be invisible, ignored or poorly understood by the general public, until a breakdown draws attention to what has been silently in the background all the while (Graham 2010). They are also operated by companies and experts who play their cards close to their chest (Graham and Marvin 2001). The space in between infrastructural arrangements is neither unorganized nor free of technology. The two scenarios examined here indicate how differently the EV can be enacted as energy infrastructure, entailing contrasting notions of (distributed) agency (Rammert 2012) between human and non-human elements (Latour 2005). They also invoke and enact diverging imaginaries of what constitutes a good life in a sustainable society based on renewable energy.

Both scenarios, even though they may seem antagonistic, imply and expect changes in user behavior within a technologically dense and highly networked environment. There is no surprise in saying that everyday life has become vastly more integrated into communication systems. Infrastructures such as the electrical power grid and road transportation have hardly moved in that direction or are just about to do so. The obvious reasons for this inertia are the extremely high costs of transformation, which reduce market incentives, if there is any competition allowed at all. Innovation studies offer explanations such as "lock-in effects" (Unruh 2000) and "path dependencies" (Garud and Karnøe 2001) of such infrastructures. Many scholars are now asking how this inertia can be overcome, how new sustainable pathways toward decarbonization can be created (Moulaert et al. 2007; Fuchs et al. 2012).

The framework of sociotechnical imaginaries calls for a different set of questions. It draws attention to the cultural space in between large-scale systems that has been opened up through communication and information technologies (Herman, Hadlaw, and Swiss 2015). How will the access to and the control of emergent interfaces between previously separate areas of energy consumption - electricity and mobility - be arranged? What happens when societies become more infrastructuralized, deeper entangled within symbiotic, "urban assemblages" (Farias and Bender 2010)? Will more sophisticated buildings, grids, and cities create further backdoors for malicious attacks? Strong concerns have been raised regarding the information security and privacy of smart homes and appliances (Friedewald and Pohoryles 2013). Hackers have successfully manipulated advanced driver assistance systems.

The increasing connectivity of infrastructural agents opens up new possibilities as well as discontents. Although the average driver might not have realized it yet, cars are about to turn into interconnected computers in the same way mobile phones did. These developments increase the technological density of everyday interactions within such arrangements as it requires ICT and other components that have become popular under the catch phrase "internet of things" (Gubbi et al. 2013). Keeping up with complexity might mean allowing infrastructure operators and service providers to generate a surplus of control within these areas of life. From the engineering perspective, more control within a more dynamic system is the only reasonable path to pursue. The continuous monitoring, balancing, and re-channeling of electricity is what keeps the grid operating - and prevents blackouts. Losing control over a decentralized grid with many mobile variables could mean millions of people sitting in the dark. 
Driving, as a potentially "off the grid" activity, embodied in the somewhat naive image of automobile independence, becomes part of a larger, complicated network that exceeds the context of local experience and requires remote management. Agency has always been tied to material interrelations. Cars undoubtedly need roads, gas stations, and repair facilities. Meticulously regulated roads and highways have come to dominate urban and rural landscapes with hardly any place left out. Yet, refueling neither requires the permanent monitoring of the user's activities nor does it rely on internet-based software and centrally stored profiles in order to make it work. In that regard, the "swarm" and the "autarky" scenarios converge. Both produce sophisticated and technologically dense environments. The question does not seem to be whether or not grids and networks will shape a sustainable low-carbon "system-of-systems." It is, rather, how large, how open, how private, how accessible, and how resilient these networks are going to be. Most importantly: who will built, own, and operate them?

\section{Conclusion}

Both the electrification of transportation and the transformation of the energy infrastructure remain challenges to which there is no definite solution. In this article, instead of schematizing the enabling and impeding factors in these developments, I have focused on the multiplicity of competing imagined futures attached to a specific technological vision vehicle-to-grid - within the German transition context. Although the attempt to bring the electric car to Germany's roads has failed so far, the image of what the next generation of EVs could achieve has changed. A new set of players, such as grid operators, utilities, and ICT companies, has become interested in cars. In order to break away from the traditional imaginary around the car, these challengers as well as mobility experts and futurists have envisioned a greater purpose for the EV altogether in terms of a symbiosis of mobility, energy, and communication technology. They have shifted the focus of attention away from the individual driver's desires to the vehicle's larger role within the overall transition toward a sustainable society. In doing so, they infused new blood into the veins of the political "expectations life-cycle" (van Lente 1993) of the EV.

Looking at sales numbers or around the streets, one might not notice any disruptive changes. But from the pre-commercial niche, the electricity- and ICT-based actors are not only trying to seize the imaginative space of private transportation; they have, at the same time, mobilized plenty of capital, patents, and workers around these ideas and research sites. The integration of EVs in smart grid infrastructure has become a major concern in both governmental and corporate R\&D funding. Dozens of state-subsidized public-private partnerships have been formed over the past few years. Such material enactments of the mostly discursive construction of the EV as energy infrastructure delineate possible trajectories toward a decarbonized, sustainable society as it is currently being discussed. Therefore, they provide a useful analytical opportunity for the in-depth exploration of specific transformation scenarios.

So far, little work has been done that describes the interaction between imaginaries as shared understandings of collective futures and the concrete ways in which actors coproduce and stabilize them in experimental settings outside the laboratory. I have demonstrated here how two exemplary enactments reflect unarticulated assumptions about the involved technologies, their purpose, and their prospective users. Both groups of actors tap into different pre-existing collective cultural currents. The variety of imagined futures reflects the plurality of contemporary societies. This plurality results not only from the diversity of values but from the co-existing layers of discourses, politics, and 
materiality as well. The question then becomes how groups of actors align with different poles of imagination. Sociotechnical imaginaries bring together historical, cultural, and cognitive components in ways that turn them into powerful forces. Not every vision becomes an imaginary.

Sociotechnical imaginaries convey collective understandings of forms of social life, including shared notions of self-determination, ownership, living arrangements, privacy, and control. These assemblages materialize through the performing of such desirable futures. In turn, the repeated enactment might change such notions in the long run. The introduced "swarm" and "autarky" scenarios can be viewed as competing enactments. Even though both R\&D ventures adhere to the same technological vision of a symbiosis between sociotechnical systems, they tap into contrasting cultural currents. One invokes the image of seamless interconnectivity, synergy, and delegation to higher order systems. The other is associated with the notion of autonomy and self-determination in today's life that is imbued with technology.

From the perspective of the innovators, transportation might present another piece in the growing patchwork of what has been called "disruptive" or "converging" technologies. It has remained in a slumber for the past decades and is now about to wake up. The growing interconnectivity among previously separate infrastructures opens up new realms of possibility, while increasing the technological density of everyday interactions. From the perspective of electrical grids and communications networks, there is a need to generate new channels and strategies of control to keep up with the escalating complexity. Fundamental questions about a desirable collective future appear in issues that emerge around routine practices of mobility and energy consumption such as convenience versus control or ownership versus delegation.

Scholars and policy experts can facilitate a reflexive debate on these issues, but cannot predict how innovations will play out eventually, when companies and users appropriate them to their respective needs. Similarly, probing sociotechnical imaginaries empirically will not illuminate new pathways into sustainable futures. Instead, they bring attention to the co-dependence between concrete technological developments and the less tangible, but often competing cultural underpinnings with which actors can align or where tension might arise. Tracing the re-imagination of energy and mobility cultures remains a longterm goal for researchers as well as policymakers. The imaginaries that shape the seemingly "hard" and "soft" components within large sociotechnical systems always entail assumptions about people, their behavior, and what represents a desirable society at large. Looking at these assumptions and blind spots from an imaginaries perspective could help engineers, scholars, and policymakers to become more aware of them and open them up to debate.

\section{Acknowledgements}

Special thanks to Werner Rammert, Nona Schulte-Römer, and Janine Bernhardt for reviewing an early draft of this paper, anonymous referees for their comments, and Roisin Cronin and Jacob Watson for their editorial support.

\section{Notes}

1. There are some remarkable, but slightly dated exceptions, which highlight the social, political, and semantic dimensions of previous attempts to electrify transportation in France, the USA, and other countries (Callon 1980; Brown 2001; Hård and Knie 2001). 
2. Most scientists and international organizations agree that in order to mitigate climate change, extraordinary measures have to be taken to reduce $\mathrm{CO}_{2}$ emissions (IEA 2009; IPCC 2015; OECD/ITF 2015). In its Energy Roadmap 2050, the European Union presented ambitious climate goals. By the year 2050 , it aims at a reduction by $80-95 \%$ in comparison to the levels registered in 1990. A decarbonization to this degree requires an estimated share of renewable energy sources in electricity consumption of nearly 97\% (European Commission 2011, 12). The report suggests drastic cuts in the transportation sector as well. In order to meet the suggested goal, at least $65 \%$ of traffic on the streets would to need be fueled by carbon-free energy (European Commission 2011, 6). It has become self-evident among policymakers and also scholars that in order to achieve this vision, the highly resilient sociotechnical regime based on fossil fuels will have to be replaced by an economy and infrastructure that hinges on renewable energy sources such as wind, solar, and hydraulic power (Haas, Watson, and Eichhammer 2008; Rohracher 2008).

3. The literature on "smart" vehicle-grid interactions is abundant and has been reviewed several times, concluding that the technology cannot keep up with its promise yet (Mullan et al. 2012; Habib, Kamran, and Rashid 2015; Liu et al. 2015). V2G requires bidirectional battery charging, a technology that asks for its own plug features, software standards, and server systems that combine large numbers of EVs into distributed virtual networks of batteries. Critics object that this approach carries significant risks and costs, while providing little benefit for the grid (Srivastava, Annabathina, and Kamalasadan 2010), not to mention for drivers. Batteries could degrade or fail, making V2G technically unreliable and economically unfeasible, so the counterargument goes.

\section{References}

Acatech. 2010. "Wie Deutschland zum Leitanbieter für Elektromobilität werden kann: Status quo Herausforderungen - Offene Fragen." Acatech bezieht Position 6.

Anderson, Benedict. 1983 2006. Imagined Communities: Reflections On the Origin and Spread of Nationalism. Rev. ed. London: Verso.

Anderson, Curtis D., and Judy Anderson. 2010. Electric and Hybrid Cars: A History. 2nd ed. McFarland: Jefferson N.C.

Appadurai, Arjun. 2013. The Future as Cultural Fact: Essays on the Global Condition. London: Verso Books.

Bakker, Sjoerd, and Jan J. Trip. 2013. "Policy Options to Support the Adoption of Electric Vehicles in the Urban Environment." Transportation Research Part D: Transport and Environment 25: $18-23$.

Bijker, Wiebe E., Thomas P. Hughes, and Trevor Pinch, eds. 1987 2012. The Social Construction of Technological Systems: New Directions in the Sociology and History of Technology. Anniversary ed. Cambridge: MIT Press.

BMWi. 2015. "Erneuerbare Energien im Jahr 2014: Erste Daten zur Entwicklung der erneuerbaren Energien in Deutschland auf Grundlage der Angaben der Arbeitsgruppe Erneuerbare EnergienStatistik." Last modified September 4, 2015.

Borup, Mads, Nik Brown, Kornelia Konrad, and Harro van Lente. 2006. "The Sociology of Expectations in Science and Technology." Technology Analysis \& Strategic Management 18 (3-4): 285-298. doi:10.1080/09537320600777002.

Brown, Mark B. 2001. "The Civic Shaping of Technology: California's Electric Vehicle Program." Science, Technology \& Human Values 26 (1): 56-81. doi:10.1177/016224390102600103.

Brown, Nik. 2003. "Hope Against Hype: Accountability in Biopasts, Presents and Futures." Science Studies 16 (2): 3-12. http://www.york.ac.uk/media/satsu/documents-papers/Brown-2003-hype. pdf.

Buchan, David. 2012. The Energiewende: Germany's Gamble. SP 26. Oxford: Oxford Institute for Energy Studies.

Bundesregierung. 2009. "Nationaler Entwicklungsplan Elektromobilität." https://www.bmbf.de/ files/nationaler_entwicklungsplan_elektromobilitaet.pdf.

Bundesregierung. 2011. "Regierungsprogramm Elektromobilität." https://www.bmbf.de/files/ programm_elektromobilitaet.pdf.

Callon, Michel. 1980. "The State and Technical Innovation: A Case-study of the Electrical Vehicle in France." Research Policy 9 (4): 358-376. 
Callon, Michel. 1987 2012. "Society in the Making: The Study of Technology as a Tool for Sociological Analysis." In The Social Construction of Technological Systems: New Directions in the Sociology and History of Technology, edited by Wiebe E. Bijker, Thomas P. Hughes, and Trevor Pinch. Anniversary ed., 77-97. Cambridge: MIT Press.

Canzler, Weert. 2008. "The Paradoxical Nature of Automobility." In Tracing Mobilities: Towards a Cosmopolitan Perspective, edited by Weert Canzler, Vincent Kaufmann, and Sven Kesselring, 105-118. Transport and Society. Aldershot: Ashgate.

Charmaz, Kathy. 2006. Constructing Grounded Theory: A Practical Guide Through Qualitative Analysis. Reprinted. London: SAGE.

Clarke, Adele E. 2005. Situational Analysis: Grounded Theory After the Postmodern Turn. Thousand Oaks, CA: SAGE.

Comor, Edward. 2011. "Contextualizing and Critiquing the Fantastic Prosumer: Power, Alienation and Hegemony." Critical Sociology 37 (3): 309-327. doi:10.1177/0896920510378767.

Corbin, Juliet M., and Anselm L. Strauss. 2008. Basics of Qualitative Research: Techniques and Procedures for Developing Grounded Theory. 3rd ed. Los Angeles, CA: Sage.

Coutard, Olivier, and Simon Guy. 2007. "STS and the City: Politics and Practices of Hope." Science, Technology \& Human Values 32 (6): 713-734. doi:10.1177/0162243907303600.

Dierkes, Meinolf, Ute Hoffman, and Lutz Marz. 1996. Visions of Technology: Social and Institutional Factors Shaping the Development of New Technologies. New York: St. Martin's Press.

Draucker, Claire B., Donna S. Martsolf, Ratchneewan Ross, and Thomas B. Rusk. 2007. "Theoretical Sampling and Category Development in Grounded Theory." Qualitative Health Research 17 (8): 1137-1148. doi:10.1177/1049732307308450.

Egyedi, Tineke M., and Donna C. Mehos, eds. 2012. Inverse Infrastructures: Disrupting Networks from Below. Cheltenham: Edward Elgar.

European Commission. 2011. "Energy Roadmap 2050." Last modified September 3, 2015. https:// www.kowi.de/Portaldata/2/Resources/fp7/coop/com-2011-Energy-Roadmap-2050-en.pdf.

Farias, Ignacio, and Thomas Bender, eds. 2010. Urban Assemblages: How Actor-Network Theory Changes Urban Studies. Questioning Cities. London: Routledge.

Featherstone, Mike, ed. 2004. “Automobilities.” Special Issue, Theory, Culture \& Society 21 (4-5). doi:10.1177/0263276404046058.

Felt, Ulrike. 2015. "Keeping Technologies Out: Sociotechnical Imaginaries and the Formation of Austria's Technopolitical Identity." In Dreamscapes of Modernity: Sociotechnical Imaginaries and the Fabrication of Power, edited by Sheila Jasanoff, and Sang-Hyun Kim, 103-125. Chicago: The University of Chicago Press.

Ferguson, James. 2005. "Seeing Like an Oil Company: Space, Security, and Global Capital in Neoliberal Africa." American Anthropologist 107 (3): 377-382. http://www.jstor.org/stable/ 3567023.

Fraunhofer ISI. 2001. "Greenhouse Gas Reductions in Germany and the UK - Coincidence or Policy Induced? An Analysis for International Climate Policy.” Last modified September 5, 2015.

Friedewald, Michael, and Ronald J. Pohoryles. 2013. "Technology and Privacy." Innovation: The European Journal of Social Science Research 26 (1-2): 1-6. doi:10.1080/13511610.2013. 768011.

Fuchs, Gerhard, Nele Hinderer, Gregor Kungl, and Mario Neukirch. 2012. "Adaptive Capacities, Path Creation and Variants of Sectoral Change: The Case of the Transformation of the German Energy Supply System.” SOI Discussion Paper 2.

Garud, Raghu, and Peter Karnøe, eds. 2001. Path Dependence and Creation. LEA's Organization and Management Series. Mahwah, NJ: Lawrence Erlbaum Associates.

Geels, Frank W. 2012. "A Socio-technical Analysis of Low-carbon Transitions: Introducing the Multi-level Perspective into Transport Studies.” Journal of Transport Geography 24: 471-482.

Graham, Stephen. 2010. Disrupted Cities: When Infrastructure Fails. New York: Routledge.

Graham, Stephen, and Simon Marvin. 2001. Splintering Urbanism: Networked Infrastructures, Technological Mobilities and the Urban Condition. London: Routledge.

Grijalva, Santiago, and Muhammad U. Tariq. 2011. Prosumer-Based Smart Grid Architecture Enables a Flat, Sustainable Electricity Industry. Piscataway: IEEE.

Gross, Matthias, and Rüdiger Mautz. 2015. Renewable Energies. London: Routledge Taylor \& Francis Group. 
Gubbi, Jayavardhana, Rajkumar Buyya, Slaven Marusic, and Marimuthu Palaniswami. 2013. "Internet of Things (IoT): A Vision, Architectural Elements, and Future Directions." Future Generation Computer Systems 29 (7): 1645-1660. doi:10.1016/j.future.2013.01.010.

Haas, Reinhard, Jim Watson, and Wolfgang Eichhammer, eds. 2008. "Transition towards Sustainable Energy Systems.” Special issue, Energy Policy 36 (11): 4009-4298.

Habib, Salman, Muhammad Kamran, and Umar Rashid. 2015. "Impact Analysis of Vehicle-to-Grid Technology and Charging Strategies of Electric Vehicles on Distribution Networks: A Review." Journal of Power Sources 277: 205-214.

Hård, Mikael, and Andreas Knie. 2001. "The Cultural Dimension of Technology Management: Lessons from the History of the Automobile." Technology Analysis \& Strategic Management 13 (1): 91-103. doi:10.1080/09537320120040464.

Hecht, Gabrielle. 2009. The Radiance of France: Nuclear Power and National Identity After World War II. Inside Technology. Cambridge: MIT Press.

Herman, Andrew, Jan Hadlaw, and Thomas Swiss, eds. 2015. Theories of the Mobile Internet: Materialities and Imaginaries. Routledge Studies in New Media and Cyberculture 24. New York: London; RoutledgeTaylor \& Francis Group.

Hilgartner, Stephen. 2015. "Capturing the Imaginary: Vanguards, Visions and the Synthetic Biology Revolution." In Science and Democracy: Making Knowledge and Making Power in the Biosciences and Beyond, edited by Stephen Hilgartner, Clark Miller, and Rob Hagendijk, 3355. Genetics and Society. London: Routledge.

Hine, Christine. 2007. "Multi-sited Ethnography as a Middle Range Methodology for Contemporary STS.” Science, Technology \& Human Values 32 (6): 652-671. doi:10.1177/0162243907303598.

Hommels, Anique. 2005. "Studying Obduracy in the City: Toward a Productive Fusion between Technology Studies and Urban Studies." Science, Technology \& Human Values 30 (3): 323351. doi:10.1177/0162243904271759.

Huenteler, Joern, Tobias S. Schmidt, and Norichika Kanie. 2012. "Japan's Post-Fukushima Challenge: Implications from the German Experience on Renewable Energy Policy.” Energy Policy 45: 6-11.

IEA. 2009. Transport Energy and $\mathrm{CO}_{2}$ : Moving Toward Sustainability. Paris: OECD/IEA.

IPCC. 2015. Climate Change 2014: Synthesis Report. Geneva: Intergovernmental Panel on Climate Change.

Jasanoff, Sheila. 2015. "Future Imperfect: Science, Technology, and the Imaginations of Modernity." In Dreamscapes of Modernity: Sociotechnical Imaginaries and the Fabrication of Power, edited by Sheila Jasanoff, and Sang-Hyun Kim, 1-33. Chicago: The University of Chicago Press.

Jasanoff, Sheila, and Sang-Hyun Kim. 2009. "Containing the Atom: Sociotechnical Imaginaries and Nuclear Power in the United States and South Korea." Minerva 47 (2): 119-146. doi:10.1007/ s11024-009-9124-4.

Jasanoff, Sheila, and Sang-Hyun Kim. 2013. "Sociotechnical Imaginaries and National Energy Policies." Science as Culture 22 (2): 189-196. doi:10.1080/09505431.2013.786990.

Jasanoff, Sheila, and Sang-Hyun Kim, eds. 2015. Dreamscapes of Modernity: Sociotechnical Imaginaries and the Fabrication of Power. Chicago, IL: The University of Chicago Press.

Keller, Reiner. 2012. Doing Discourse Research: An Introduction for Social Scientists. London: Sage.

Kempton, Willett, Jasna Tomic, Steven Letendre, Alec Brooks, and Timothy Lipman. 2001. "Vehicle-to-Grid Power: Battery, Hybrid, and Fuel Cell Vehicles as Resources for Distributed Electric Power in California." Recent Work. http://escholarship.org/uc/item/0qp6s4mb.

Konrad, Kornelia. 2006. "The Social Dynamics of Expectations: The Interaction of Collective and Actor-Specific Expectations on Electronic Commerce and Interactive Television." Technology Analysis \& Strategic Management 18 (3-4): 429-444. doi:10.1080/09537320600777192.

Laird, Frank N. 2003. "Constructing the Future: Advocating Energy Technologies in the Cold War." Technology and Culture 44 (1): 27-49. doi:10.1353/tech.2003.0030.

Lakoff, George, and Mark Johnson. 2003. Metaphors We Live By. Chicago, IL: University of Chicago Press.

Latour, Bruno. 1986. "Visualization and Cognition: Drawing Things Together." In Knowledge and Society: Studies in the Sociology of Culture Past and Present, edited by Elisabeth Long and Henrika Kuklick, 6 vols, 1-40. Knowledge and Society. Greenwich, CT: JAI Press; Distributed by JAICON Press. 
Latour, Bruno. 2005. Reassembling the Social: An Introduction to Actor-Network-Theory. Clarendon Lectures in Management Studies. Oxford: Oxford University Press.

Law, John. 1994. Organizing Modernity. Oxford: Blackwell.

van Lente, Harro. 1993. Promising technology: The Dynamics of Expectations in Technological Developments. Enschede: Faculteit Wijsbegeerte en Maatschappijwetenschappen.

LeVine, Steve. 2015. "Mass-Market Electric Cars Will Go 200 Miles, But Are Still a Long Way from Being Profitable." Accessed September 7, 2015. http://qz.com/411066/mass-market-electriccars-will-go-200-miles-but-are-still-a-long-way-from-being-profitable/

Liu, Liansheng, Fanxin Kong, Xue Liu, Yu Peng, and Qinglong Wang. 2015. "A Review on Electric Vehicles Interacting with Renewable Energy in Smart Grid.” Renewable and Sustainable Energy Reviews 51: 648-661.

Loisel, Rodica, Guzay Pasaoglu, and Christian Thiel. 2014. "Large-Scale Deployment of Electric Vehicles in Germany by 2030: An Analysis of Grid-to-Vehicle and Vehicle-to-Grid Concepts." Energy Policy 65: 432-443.

Mitchell, William J., Chris Borroni-Bird, and Lawrence D. Burns. 2010. Reinventing the Automobile: Personal Urban Mobility for the $21^{\text {st }}$ Century. Cambridge: Massachusetts Institute of Technology.

Moulaert, Frank, Flavia Martinelli, Sara González, and Erik Swyngedouw. 2007. "Social Innovation and Governance in European Cities: Urban Development Between Path Dependency and Radical Innovation.” European Urban and Regional Studies 14 (3): 195-209. doi:10.1177/ 0969776407077737.

Mullan, Jonathan, David Harries, Thomas Bräunl, and Stephen Whitely. 2012. "The Technical, Economic and Commercial Viability of the Vehicle-to-Grid Concept: Special Section: Frontiers of Sustainability." Energy Policy 48: 394-406.

NPE. 2010. "Zwischenbericht der Nationalen Plattform Elektromobilität." https://www.bdew.de/ internet.nsf/id/E5CDE6B07CA23EEFC125783E005458AE/\$file/Zwischenbericht\% 20Nationale\%20Plattform\%20Elektromobilit\%C3\%A4t_30.11.2010.pdf.

NPE. 2014. "Fortschrittsbericht 2014: Bilanz der Marktvorbereitung." https://www.bmbf.de/files/ NPE Fortschrittsbericht 2014 barrierefrei.pdf.

OECD/ITF. 2015. ITF Transport Öutlook 2015. Paris: International Transport Forum.

Oudshoorn, Nelly, and Trevor Pinch. 2003. How Users Matter: The Co-Construction of Users and Technologies. Inside Technology. Cambridge: MIT Press.

Rammert, Werner. 2002. "The Cultural Shaping of Technologies and the Politics of Technodiversity." In Shaping Technology, Guiding Policy: Concepts, Spaces, and Tools, edited by Knut H. Sørensen and Robin Williams, 173-196. Cheltenham: Elgar. http://en.scientificcommons.org/ 58595944.

Rammert, Werner. 2012. "Distributed Agency and Advanced Technology." In Agency Without Actors? New Approaches to Collective Action, edited by Jan-Hendrik Passoth, Birgit M. Peuker, and Michael W. J. Schillmeier, 98-112. Routledge Advances in Sociology 58. London: Routledge.

Rammler, Stephan. 2008. "The Wahlverwandtschaft of Modernity and Mobility." In Tracing Mobilities: Towards a Cosmopolitan Perspective, edited by Weert Canzler, Vincent Kaufmann, and Sven Kesselring, 57-76. Transport and Society. Aldershot: Ashgate.

RAP. 2015. "Report on the German Power System: Version 1.0. Study Commissioned by Agora Energiewende." Accessed September 5, 2015. http://www.agora-energiewende.de/fileadmin/ downloads/publikationen/CountryProfiles/Agora_CP_Germany_web.pdf

Ritzer, George, and Nathan Jurgenson. 2010. "Production, Consumption, Prosumption: The Nature of Capitalism in the Age of the Digital 'Prosumer."' Journal of Consumer Culture 10 (1): 13-36. doi:10.1177/1469540509354673.

Rogers, Everett M. 1962 1983. Diffusion of Innovations. 3rd ed. New York: Free Press; Collier Macmillan.

Rohracher, Harald. ed. 2008. "Transforming Energy Systems Towards Sustainability: Critical Issues from a Socio-Technical Perspective." Special issue, International Journal of Environmental Technology and Management 9 (2/3): 141-315.

Rowland, Nicholas J., and Jan-Hendrik Passoth. 2015. "Infrastructure and the State in Science and Technology Studies." Social Studies of Science 45 (1): 137-145. doi:10.1177/ 0306312714537566. 
Rucht, Dieter, and Jochen Roose. 2001. "Neither Decline Nor Sclerosis: The Organisational Structure of the German Environmental Movement." West European Politics 24 (4): 55-81. doi:10.1080/ 01402380108425465.

Schreuer, Anna, and Daniela Weismeier-Sammer. 2010. "Energy Cooperatives and Local Ownership in the Field of Renewable Energy Technologies: A Literature Review." RiCC - Research Reports 4. http://epub.wu. ac.at/2897.

Scott, James C. 1998. Seeing Like a State: How Certain Schemes to Improve the Human Condition Have Failed. The Yale ISPS series. New Haven: Yale University Press.

Sierzchula, William, Sjoerd Bakker, Kees Maat, and Bert van Wee. 2014. "The Influence of Financial Incentives and Other Socio-Economic Factors on Electric Vehicle Adoption." Energy Policy 68: 183-194.

Sovacool, Benjamin K., and Richard F. Hirsh. 2009. "Beyond Batteries: An Examination of the Benefits and Barriers to Plug-in Hybrid Electric Vehicles (PHEVs) and a Vehicle-to-Grid (V2G) Transition.” Energy Policy 37 (3): 1095-1103. doi:10.1016/j.enpol.2008.10.005.

Srivastava, Anurag K., Bharath Annabathina, and Sukumar Kamalasadan. 2010. "The Challenges and Policy Options for Integrating Plug-in Hybrid Electric Vehicle into the Electric Grid." The Electricity Journal 23 (3): 83-91. doi:10.1016/j.tej.2010.03.004.

Taylor, Charles. 2004. Modern Social Imaginaries. Public Planet Books. Durham: Duke University Press.

Unruh, Gregory C. 2000. “Understanding Carbon Lock-In.” Energy Policy 28 (12): 817-830. doi:10. 1016/S0301-4215(00)00070-7.

Urry, John. 2004. “The 'System' of Automobility.” Theory, Culture \& Society 21 (4-5): 25-39. doi:10.1177/0263276404046059.

Volkswagen. 2014, April 16. "Intelligente Energie: 20 Elektroautos mit SchwarmStrom starten Flottenversuch in Berlin." News release. April 16, 2014. Accessed September 9, 2015. http:// www.erneuerbar-mobil.de/de/projekte/foerderung-von-vorhaben-im-bereich-der-elektromobili taet-ab-2012/kopplung-der-elektromobilitaet-an-erneuerbare-energien-und-deren-netzintegrati on/projektflyer-netzintergration/pm-flottenstart-vw-inees.pdf 